\title{
P.3. Усеев
}

\section{МУЛЬТИРЕЖИМНОСТЬ ИСПРАВИТЕЛЬНЫХ УЧРЕЖДЕНИЙ: ПРИЧИНЫ, КЛАССИФИКАЦИЯ, ПЕРСПЕКТИВЫ}

\begin{abstract}
В последние десятилетия в исправительных учреждениях уголовно-исполнительной системы наблюдается тенденция мультирежимности. Фактически каждое учреждение размещает на своей территории тот или иной объект, который характеризуется другим порядком исполнения и отбывания наказания или содержания под стражей. Этот порядок отличается от установленного порядка основного учреждения. Предлагается выявить причины мультирежимности исправительных учреждений, провести ее классификацию и определить дальнейшие перспективы.
\end{abstract}

Ключевые слова: мультирежимность, гибридность, комплексность, исправительное учреждение, уголовно-исполнительная система.

Современная уголовно-исполнительная система России (далее - УИС) представлена широким спектром органов, учреждений, предприятий и иных подразделений. Фактически все они в большей или меньшей степени выполняют задачи по обеспечению исполнения и отбывания уголовных наказаний и содержания под стражей.

Указанная выше задача является для УИС магистральной. Ее выполняют специально созданные места изоляции - исправительные учреждения (далее - ИУ) и следственные изоляторы (далее - СИЗО).

Бесспорно, лишение свободы и содержание под стражей относительно иных мер государственного принуждения являются с позиции реализации общественных отношений и происходящих процессов самыми сложными и разнообразными. Во многом это касается установленного порядка исполнения и отбывания наказания (содержания под стражей) режима, который в т.ч. лежит в основе вида ИУ.

В настоящий момент российская уголовно-исполнительная система обладает широкой системой статических мест изоляции. В нее входят исправительные колонии (далее - ИК) общего, строгого и особого режимов, колонии-поселения; воспитательные колонии (далее - ВК); тюрьмы; лечебнопрофилактические учреждения (далее - ЛПУ); лечебные исправительные учреждения (далее - ЛИУ) и СИЗО. По определению - эти учреждения, предназначенные для исполнения (отбывания) лишения свободы и содержания под стражей, являются самостоятельными и имеют статус юридического лица. Априори каждое учреждение воспринимается относительно закрепленного за ним вида режима. Однако, как показывает практика, это не совсем так, поскольку отдельное место изоляции УИС может представлять из себя систему видов учреждений (режимов). Речь идет о состояниях и явлениях, которые наука обозначила как «мультирежимность» [1, с. 9-17], «гибридность» [2, с. 7-11] и «комплексность» [3, с. 40].

На сегодняшний день литература рассматривает такие вопросы. Еще в 2008 г. В.А. Уткин отмечал, что «будущие места лишения свободы в России в большинстве своем воплотят в себе черты тюрьмы и колонии, превратившись в учреждения «гибридного» типа» [4, с. 149-156].

В чем же причины гибридизации учреждений? Попробуем разобраться.

Во-первых, это география российских ИУ (СИЗО) и значительные расстояния между ними. В настоящий момент места изоляции покрывают практически всю территорию страны'. Они размещены в каждом субъекте РФ, кроме г. Севастополя, Ненецкого автономного округа и Чукотского автономного округа. В целом же количество учреждений и их набор отчасти коррелируют с численностью населения региона, отчасти - со сложившейся системой исправительных учреждений, сохранившихся с советского периода [5, с. 7]. Отсюда большие расстояния между местами изоляции, которые даже в пределах одного субъекта РФ могут достигать до 1700 км (Красноярский край). В этом аспекте кустовой способ размещения учреждений по-прежнему конкурирует с индивидуально расположенными местами изоляции.

Во-вторых, территориальные органы ФСИН России не располагают полным набором видов ИУ, определенных ст.ст. 74, 80 УИК РФ. В настоящий момент таких примеров по стране нет. Усугубляется это еще и тем, что с середины 2007 г. осужденные могут отбывать наказание на территории того субъекта РФ, в котором имеются условия для их размещения. По определению это может быть любой территориальный орган ФСИН России.

В-третьих, реализация практически «спящего» до 2010 г. принципа дифференциации осужденных (ч. 2 ст. 80 УИК РФ), в части, касающейся раздельного содержания лиц, впервые осужденных к лишению свободы (т.н. первоходов) от ранее отбывавших лишение свободы (т.н. второходов). В итоге только в 2010 г.

\footnotetext{
${ }^{1}$ Расстояние между самыми западными (ФКУ ИК-4, ФКУ СИЗО-3 УФСИН России по Калининградской области, п. Колосовка) и самыми восточными учреждениями УИС (ФКУ ИК-5, ФКУ СИЗО-1 УФСИН России по Камчатскому краю, г. Петропавловск-Камчатский) составляет более 7400 км, что равняется приблизительно расстоянию от Москвы до Нью-Йорка (США).
} 
между ИУ было перемещено более 153 тыс. осужденных, в том числе 112 тыс. в ИК строгого режима и 41 тыс. - общего режима [6, с. 4], в т.ч. в ИУ других регионов РФ. В результате такой дифференциации уполномоченный по правам человека в РФ констатировал нарушение прав осужденных [7].

В-четвертых, сокращение в последние годы количества ИУ и СИЗО в РФ. Всего же в ближайшие годы этот вопрос должен затронуть порядка ста учреждений по стране [8]. Так, только в 2015 г. в УИС России принято решение о ликвидации 15 ИУ и одного объединения исправительных колоний. В целом же за указанный год достигнута самая низкая численность осужденных, подозреваемых и обвиняемых в новейшей истории РФ [9, с. 4].

В принципе, на практике все указанные выше причины являются взаимосвязанными и дополняют друг друга.

Вопросы правового регулирования мультирежимности находят отражение как в международных стандартах, так и в российском уголовно-исполнительном законодательстве.

Минимальные стандартные правила обращения с заключенными 1955 г. закрепляют положение, по которому различные категории заключенных содержатся в раздельных заведениях или в разных частях одного и того же заведения (правило 8). Этот вопрос продолжают Европейские пенитенциарные правила 2006 г. Они отмечают, что для конкретных категорий заключённых должны использоваться отдельные пенитенциарные учреждения или отдельные отделения пенитенциарных учреждений (правило 104.1). В конце концов, в законодательстве РФ мультирежимность также находит отражение в части создания:

- изолированных участков с различными видами режима (ст. 74 УИК РФ);

- транзитно-пересыльных пунктов (далее - ТПП) (ст. 76 УИК РФ).

- помещений, функционирующих в режиме СИЗО на базе учреждений, исполняющих наказания (далее - ПФРСИ) (ст. 5.1 Закона РФ от 21.07.1993 г. № 5473-1 «Об учреждениях и органах, исполняющих уголовные наказания в виде лишения свободы»);

- объединений исправительных колоний (далее ОИК) (ст. 6 Закона РФ от 21.07.1993 г. № 5473-1 «Об учреждениях и органах, исполняющих уголовные наказания в виде лишения свободы»);

- изолированных участков с различными условиями отбывания наказания или видом тюремного режима (ст.ст. 87, 118, 121, 123, 125, 127, 131, 133 УИК РФ).

По мнению автора, в основе мультирежимности ИУ лежит несколько компонентов:

1. Собственно сам режим как установленный порядок исполнения и отбывания наказания в виде лишения свободы (содержания под стражей) в месте размещения изолированных лиц, а также сопутствующий ему различный объем правоограничений.
2. Архитектура мест содержания осужденных, подозреваемых и обвиняемых. Этот компонент практически базируется либо на отрядно-лагерной форме содержания лиц (общежития, жилые комнаты и помещения), либо камерно-тюремной, где центральное место занимают камеры.

3. Фортификация, т.е. система физических преград (барьеров) в форме рубежей (границ), в пределах которых содержатся разные категории осужденных, подозреваемых и обвиняемых [10, с. 38-41]. В условиях представленной нами мультирежимности рубежами фортификации будут являться ограждения изолированных участков либо ограждения, разделяющие разные виды ИУ (при условии, что они размещаются под одним охраняемым периметром).

Анализ законодательства и сложившейся практики показывает, что в настоящий момент для российских ИУ характерна достаточно широкая мультирежимность. Попробуем провести ее классификацию.

Итак, на наш взгляд, мультирежимность ИУ можно классифицировать на две большие группы:

I. Мульти режи мн ость мест отбывания наказаний и содержания под стражей УИС (межвидовая мультирежимность).

a) Размещение под охраняемым периметром территории ИУ изолированных участков, функционирующих как исправительный центр (рис. 1).

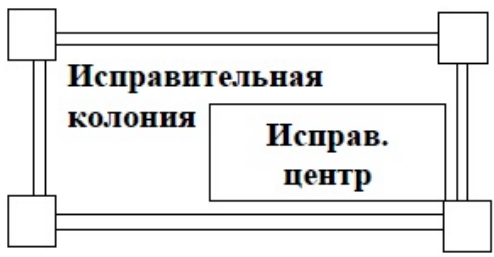

Рис. 1

Такой формат мультирежимности еще раз доказывает универсальность мест изоляции УИС, которые становятся своеобразным центром исполнения и отбывания иных наказаний. Проблемность практического воплощения в жизнь отдельных видов наказаний априори определяет обеспечительный функционал мест лишения свободы по принципу: «Если не исправительные учреждения, то кто же?» В итоге они становятся для иных мер государственного принуждения (прежде всего, наказаний) своеобразным стартапом.

Представленный вид мультирежимности является теоретическим, поскольку введение наказания в виде принудительных работ отложено до 2017 г., следовательно, места отбывания наказания - исправительные центры - сегодня не функционируют. Можно предположить, что рассматриваемые изолированные участки могут быть созданы по подобию действующих сегодня участков при ИК, функционирующих как колонии-поселения. То есть отсутствие по закону вооруженной изоляции в отношении 
осужденных к принудительным работам, ставит вопрос о необходимости их размещения за пределами охраняемого периметра базового учреждения.

Очевидно, места изоляции УИС могли бы стать стартовой площадкой для «спящего» почти 20 лет наказания в виде ареста. Сегодня литература предлагает для этого воспитательные колонии (либо территории и объекты вместо воспитательных колоний) $[1$, c. 16], в целом исправительные учреждения [11, c. 92-96]; СИЗО, тюрьмы и даже ЛИУ [12, с. 69, 70].

б) Совместное размещение нескольких самостоятельных ИУ под одним охраняемым периметром (рис. 2).

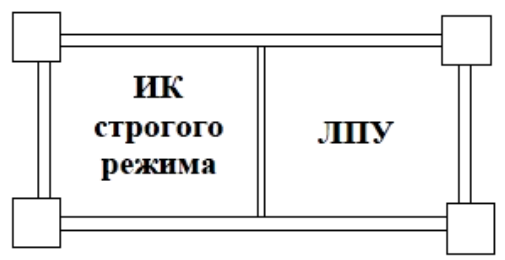

Рис. 2

Данная форма мультирежимности сложилась исторически. Становление и развитие ИУ и СИЗО страны (1930-1980-е годы) показывает, что расширение производственной базы, постоянная смена организационных структур (лагерей, пунктов, отделений, колоний), изменение видов режима учреждений вело к тому, что под одним охраняемым периметром мест лишения свободы появлялись самостоятельные участки, отделения, помещения, больницы. Некоторые из них в итоге «перерождались» в самостоятельные учреждения.

Такая мультирежимность характерна тем, что несколько учреждений, имеющих статус самостоятельных юридических лиц, размещены под одним охраняемым периметром (например, ФКУ ИК-6 (строгий режим) и ФКЛПУ ОТБ ГУФСИН России по Самарской области (туберкулезная больница)). При этом вооруженную охрану этих учреждений, как правило, обеспечивает подразделение (отдел охраны) одного из учреждений.

в) Совместное размещение нескольких самостоятельных ИУ и СИЗО под одним охраняемым периметром (рис. 3):

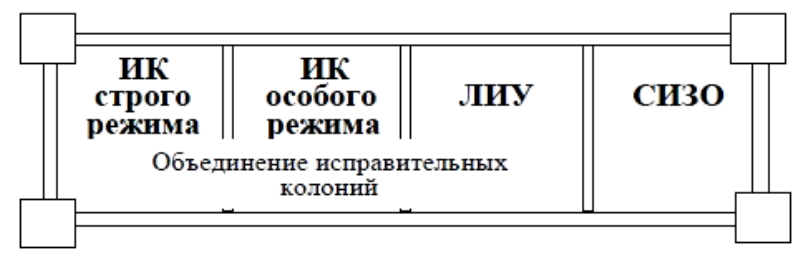

Рис. 3

Такая мультирежимность во многом является продолжением предыдущей. Причем, как показывает практика, эффект мультирежимности в таких местах изоляции УИС получал свое развитие не только в советские годы, но и в период перестройки и даже в последние десятилетия. Так, закрытие в начале 1990-х годов лечебно-трудовых профилакториев № 5 и 6 Красноярского края побудило руководство УИС региона впоследствии оборудовать на их базе три самостоятельных ИУ в структуре объединения исправительных колоний (далее - ФКУ ОИК36 ГУФСИН России по Красноярскому краю) под одним охраняемым периметром. Однако на этом мультирежимность не закончилась. Более 10 лет назад (2005 г.) объединение пополнилось СИЗО, ранее являвшимся помещением, функционирующим в режиме СИЗО. В настоящий момент на базе ФКУ ОИК-36 ГУФСИН России по Красноярскому краю под одним охраняемым периметром функционируют четыре (!) самостоятельных учреждения: ИК-5 (строгий режим), ИК-34 (особый режим), ЛИУ-35 (туберкулезная больница) и СИЗО-6.

г) Размещение под охраняемым периметром территории ИУ изолированных участков, функционирующих как ИУ с иными видами режима, в т.ч. тюрьмы (рис. 4).
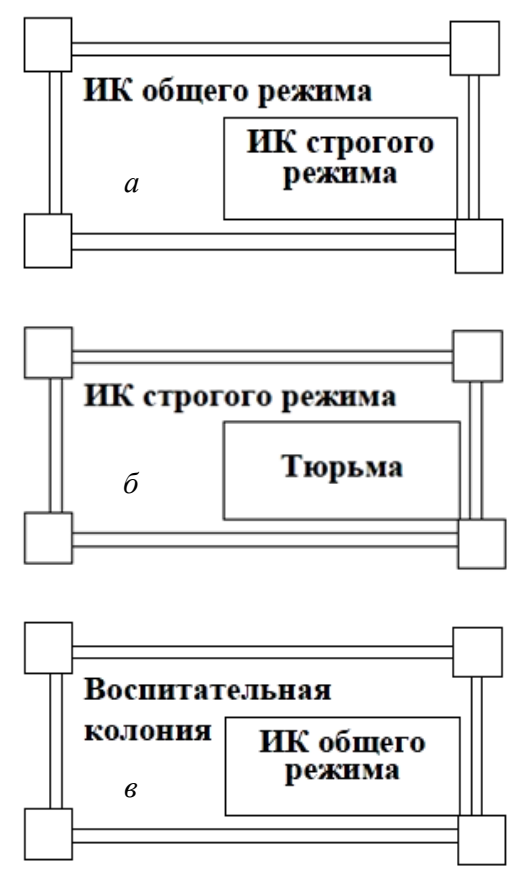

Рис. 4.3

Одна из самых распространенных форм мультирежимности в ИУ. Фактически за два с лишним года законодатель установил правило, по которому при местах изоляции УИС могли создаваться изолированные участки. Так, с 2001 г. на территории ИК вводятся изолированные участки с различными видами режима. А с 2003 г. при ВК образуются изолированные участки, функционирующие как ИК общего режима. Спустя десятилетие (лето 2013 г.) ч. 2 ст. 74 УИК РФ дополняется положением, по которому в ИК могут создаваться изолированные участки, функционирующие как тюрьма. Можно ли заявить, что «тюрьма все-таки проникает в лагерь»? 
Теперь, думаем, нет. Поскольку провозглашенная в Концепции развития УИС до 2020 г. (редакция 2010 г.) «тюрьмизация» была обречена на неудачу, а соответствующий раздел документа в сентябре 2015 г. утратил силу [13, с. 16]. Видимо поэтому, нововведения трехлетней давности никак не получат должного практического воплощения.

д) Размещение при ИУ (вне охраняемого периметра) участков, функционирующих как колониипоселения (см. рис. 5).

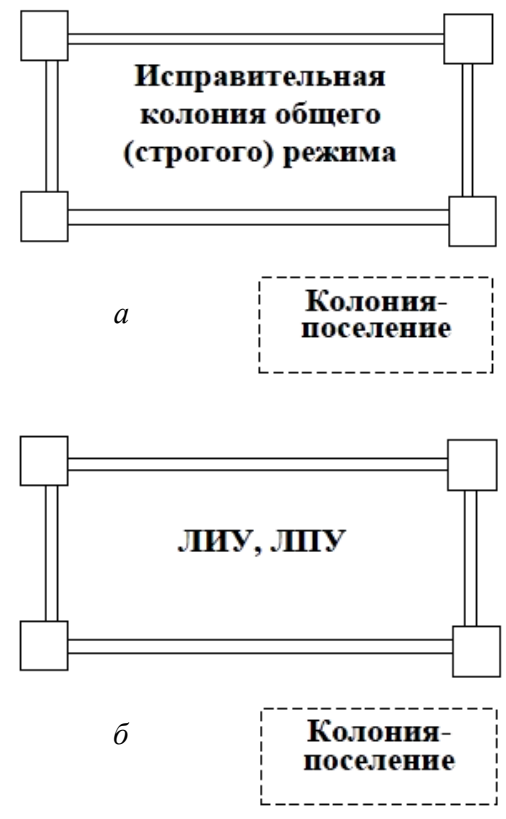

Рис. 5

Такой вид мультирежимности, как правило, направлен на обеспечение деятельности базовых учреждений (особенно ЛПУ и ЛИУ). В то же время это своеобразный элемент прогрессивной системы отбывания наказания. Поскольку положительно характеризующийся осужденный в порядке ст. 78 УИК РФ может быть переведен для отбывания наказания не в колонию-поселение, возможно в т.ч. другого региона, а в участок колонии-поселения при базовом учреждении.

Анализ географии ИУ страны показывает, что указанная форма мультирежимности приобретает сегодня в территориальных органах ФСИН России массовый характер. Можно предположить, что ФСИН России в последнее десятилетие в целях своей же безопасности избрало новый тренд, выраженный в замене осужденных, пользующихся правом передвижения без конвоя, на осужденных участка колоний-поселений при базовых ИК. Об это свидетельствует официальная статистика ФСИН России. Так, за 7 лет (с 2007 по 2013 г.) только в ИК строгого режима количество осужденных, пользующихся правом передвижения без конвоя, уменьшилось более чем в 4,5 раза с 2101 до 455 осужденных [14].
II. М у л ь т и р е ж и м н о с т ь объектов одного ИУ (внутривидовая мультирежимность).

а. Мультирежимность объектов ИУ, выполняющих обеспечительные задачи для территориального органа ФСИН России (рис. 6).
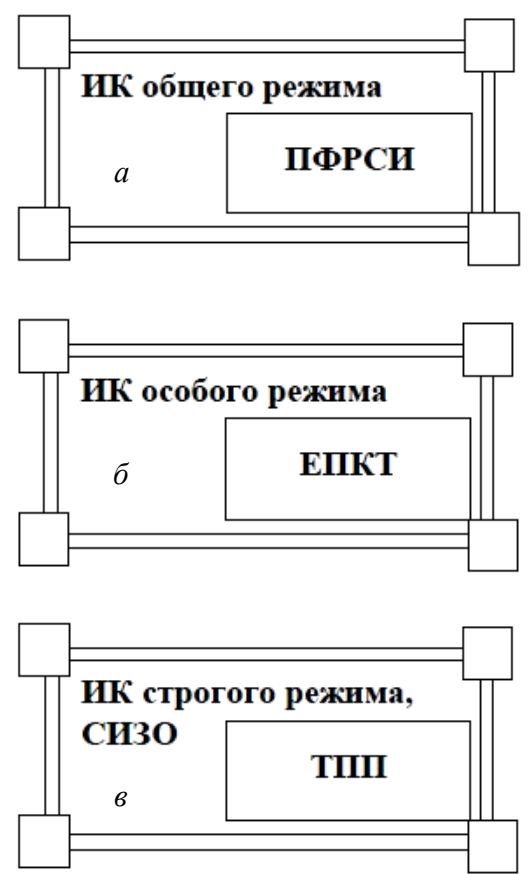

Рис. 6

Представленная форма мультирежимности определяет в своей основе обеспечительный функционал процесса изоляции личности. В этом случае ИУ либо СИЗО начинают выполнять функции, которые выходят за рамки характерных для них природных задач. Содержание же осужденных, подозреваемых и обвиняемых в помещениях, функционирующих в режиме СИЗО (далее - ПФРСИ), единых помещениях камерного типа (далее - ЕПКТ), транзитнопересыльных пунктах (далее - ТПП) традиционно воплощается в жизнь в условиях тюремно-камерной формы их содержания. Практика показывает, что если учреждение располагает дополнительными камерными площадями (помимо стандартных штрафных изоляторов и помещений камерного типа в ИК), то, очевидно, это место изоляции будет нести (несет) на своей базе дополнительную нагрузку по содержанию осужденных, подозреваемых и обвиняемых на дочерних объектах - в ПФРСИ, ЕПКТ либо ТПП.

б) Мультирежимность условий отбывания наказания в ИУ (на примере исправительных и воспитательных колоний, кроме колоний-поселений) (рис. 7).

Эффект мультирежимности прослеживается не только на уровне видов ИУ и объектов, выполняющих обеспечительные задачи (ПФРСИ и др.). По сути, сами условия отбывания наказания в ИУ и есть различный мини-режим. Конечно же, это так. 


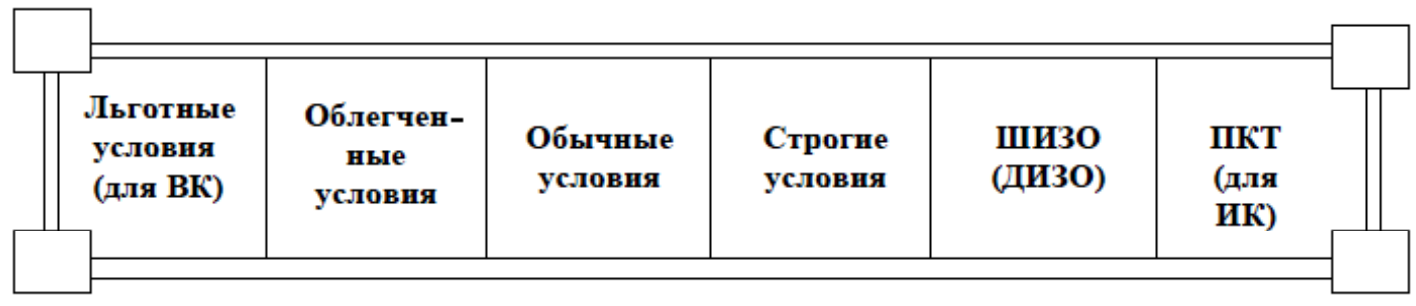

Рис. 7

Дело в том, что каждое условие отбывания наказания характеризуется своим установленным порядком, а также объемом правоограничений. По аналогии с видами ИУ возможно оценить условия отбывания наказания. Так, льготные условия в ВК и облегченные условия в ИК общего режима (при условии, что осужденные проживают и работают за пределами своих учреждений) есть своеобразный аналог условиям отбывания наказаний в отношении осужденных в колонии-поселении. В то же время содержание осужденных в ШИЗО (дисциплинарном изоляторе) - это, по сути, условия тюрьмы. Вместе с тем в мультирежимности очевидны определенные проблемы:

1. При осложнении оперативной обстановки в учреждении (например, массовые беспорядки, групповые неповиновения) в него могут быть вовлечены все категории осужденных этого учреждения, в т.ч. осужденные изолированных участков. Фактически такая ситуация имела место в июне 2015 г., когда осужденные участка колонии-поселения при ФКУ ИК-7 УФСИН России по Республике Башкортостан (г. Мелеуз) в количестве 66 человек поддержали противоправные действия осужденных указанного учреждения, отбывающих наказание в строгом режиме, а именно: забаррикадировались в жилых помещениях отряда участка колонии-поселения.

Однако на уровне самостоятельных видов ИУ, находящихся под одним охраняемым периметром, также возможны подобные негативные процессы. Так, в мае-июне 2015 г. произошедшие в ФКУ ИК-2 УФСИН России по Республике Башкортостан (г. Салават, строгий режим) массовые беспорядки и групповые неповиновения осужденных перекинулись на смежное (находящееся под одним периметром) с колонией ФКУ ЛИУ-19 для содержания осужденных, больных открытой формой туберкулеза.

2. Наличие при учреждениях изолированных участков либо смежных учреждений так или иначе может порождать неформальные контакты между разными категориями осужденных (общение, выкрики, перебросы, передачу вещей и предметов и т.д.).

3. Практический работник такого учреждения должен обладать широкими знаниями, умениями и навыками деятельности. Особенно это касается того персонала, который осуществляет свои полномочия как в камерно-тюремных условиях (например, участок ПФРСИ, тюрьмы в ИК и т.д.), так и в отрядно- лагерных (участки ИК иных режимов и т.д.). Это касается в первую очередь руководящего состава мультирежимных учреждений.

4. В отдельных случаях усложняется идентификация осужденных разных режимов, которая приводит к недовольству. Так, осужденным разных ИУ в ОИК-36 ГУФСИН России по Красноярскому краю (под одним периметром объединения расположено четыре самостоятельных учреждения) нашивают отличительные знаки (полоски из материала разных цветов). Это, по мнению отдельных осужденных указанного объединения, противоречит законодательству РФ, унижает человеческое достоинство и приносит нравственные страдания [15].

Каковы же перспективы мультирежимности ИУ?

Думается, что в условиях сокращения или даже некоторого увеличения численности осужденных, подозреваемых и обвиняемых тенденция мультирежимности учреждений продолжится. Для лиц, содержащихся в ИУ, будут сохраняться социально полезные связи. Им не придется отбывать наказание в другом ИУ иного населенного пункта или даже региона. Одновременно, такая мультирежимность ИУ выгодна с позиции материально-технического и коммунально-бытового обслуживания учреждения. Однако, по мнению автора, возникает важнейший вопрос: готова ли в среднесрочной и долгосрочной перспективе отрядно-лагерная система содержания лиц обеспечить мультирежимность учреждения?

В том виде, в котором это происходит сегодня, видимо, сможет. Вместе с тем на волне сокращений мест лишения свободы возможно увеличение мультирежимных объектов в том или ином учреждении. Думается, что здесь необходима новая концепция ИУ, которой пока нет.

Очевидно, что вопросы мультирежимности в перспективе будут строиться вокруг своеобразной конкуренции отрядно-лагерной и тюремнокамерной системы содержания осужденных, подозреваемых и обвиняемых.

В настоящий же момент вопрос о «тюрьмизации» ИУ снят с повестки дня уголовно-исполнительной политики [16]. Видимо, пока у «тюрьмы» нет возможности не только «войти в лагерь», но и заменить его. Скорее наоборот. Отрядная система в организационно-управленческом аспекте расширяется и укрупняется, поскольку получает развитие эксперимент в ряде ИУ территориальных органов ФСИН России по внедрению модели центров ис- 
правления осужденных (далее - центры). Центры создаются из двух или трех отрядов осужденных, которые, как правило, размещаются в одном жилом здании или изолированном участке [17]. Но не стоит забывать, что Концепция развития УИС до 2020 г. сохранила такой аспект, согласно которому размещение осужденных и одновременное их присутствие в многоместных общежитиях делает невозможным пресечение нежелательных контактов между ними. В свою очередь, действующие сегодня принципы раздельного содержания осужденных не позволяют эффективно решать эту проблему. В связи с этим мы считаем, что вводимые сегодня Центры (хотя бы и в экспериментальном порядке) должны учесть положения отмененных теоретических моде- лей колоний-поселений с обычным и усиленным наблюдением, разработанных ФСИН России в 2011 г. В них основным местом размещения осужденных являлась комната на 6 человек, а не общежитие [18].

Таким образом, за последние 15 лет российские ИУ сделали значительный шаг в сторону их мультирежимности. Представляется, что мультирежимность должна лечь в основу нового гибридного типа ИУ. Для этого типология тюрьмы должна стать определяющей. По мнению автора, она должна учитывать архитектурную и фортификационную концепции, концепцию надзора, а также концепцию камеры/общежития. Но это уже совсем другой вопрос, который на сегодняшний день находится в авторской проработке.

\section{ЛИТЕРАТУРА}

1. Уткин В.А. «Мультирежимные» исправительные учреждения: реальность и перспективы // Вестник Кузбасского института ФСИН России. 2014. № 4. С. 9-17.

2. Уткин B.A. Гибридные исправительные учреждения и международные стандарты // Уголовно-исполнительное право. 2014. № 2 (18). С. 7-11.

3. Горбань Д.В. «Комплексные» исправительные учреждения в пенитенциарной системе России на современном этапе ее реформирования // Актуальные вопросы борьбы с преступлениями. 2015. № 1. С. 40.

4. Уткин B.A. «Тюремный» вектор в уголовно-исполнительной системе // Отечественные записки. 2008. № 2 (41). C. $149-156$

5. Аверкина К.В. География и экономика российской пенитенциарной системы // Демоскоп Weekly. 2015. № 651-652. C. 7.

6. Реймер А.А. Концепция развития уголовно-исполнительной системы Российской Федерации до 2020 года - главный программный документ реформирования отечественной пенитенциарной системы // Вестник Владимирского юридического института. 2011. № 2. С. 4.

7. Селиверстов В.И. Куда социальный лифт теперь вывезет экс-директора ФСИН // Независимая газета. 2015. 07 апреля.

8. Петров И. ФСИН ликвидирует и реорганизует 100 колоний // Российская газета. 2015. 05 июня.

9. Обеспечено стабильное функционирование УИС // Преступление и наказание. 2016. № 4. С. 4.

10. Усеев Р.3. Понятие, формы и рубежи пенитенциарной фортификации // Уголовно-исполнительное право. 2014 . № 1. C. $38-41$.

11. Нечаев А.Д., Усалев В.В. Проблемы создания учреждений, исполняющих наказания в виде ареста // Вопросы современной юриспруденции: Сб. ст. по материалам XLVII Междунар. науч.-практич. конф. № 3 (45). Новосибирск: Издво «СибАК», 2015. С. 92-96.

12. Зубков А.И. Уголовно-исполнительное право России: теория, законодательство, международные стандарты, отечественная практика конца XIX - начала XXI века: учебник для вузов. М.: Норма, 2006. С. 69, 70.

13. Уткин B.A. Пенитенциарные стандарты Совета Европы и векторы реформирования уголовно-исполнительной системы // Уголовно-исполнительная система: право, экономика, управление. 2016. № 1. С. 16.

14. Отчет ФСИН России (форма 8-УИС) о количестве исправительных колоний, лечебных исправительных и лечебнопрофилактических учреждений, больниц, численности, составе и движении осужденных, содержащихся в них за 2007. М.: ФСИН России, 2008. С. 1.

15. Решение по делу Дудинского районного суда Красноярского края № 2-601/2011 M-559/2011 [Электронный ресурс] // Росправосудие [Официальный сайт]. URL: https://rospravosudie.com/court-dudinskij-rajonnyj-sud-krasnoyarskij-krajs/act-407292311/ (дата обращения: 17.05.2016).

16. О внесении изменений в Концепцию развития уголовно-исполнительной системы Российской Федерации до 2020 года: Распоряжение Правительства РФ от 23.09.2015 г. № 1877-р // Собрание законодательства РФ. 2015. № 40. Ст. 5581.

17. О проведении эксперимента по апробации модели Центра исправления осужденных исправительного учреждения: Распоряжение ФСИН России от 30.04.2015 г. № 63-р. [Электронный ресурс] // ФСИН России [Официальный сайт]. URL: http://www.fsin.su/Original_doc/model_ispravitelnogo_centra.doc. (дата обращения: 17.05.2016).

18. Модель колоний-поселений с обычным и усиленным наблюдением // Информационное письмо ФСИН России от 26.05.2011 г. № 5-9796-05т. М.: ФСИН России, 2011. С. 1. 


\section{MULTI-REGIME CORRECTIONAL FACILITIES: CAUSES, CLASSIFICATION, PROSPECTS}

\section{Ugolovnaya yustitsiya - Russian Journal of Criminal Law, 2016, 2(8), 81-88. DOI 10.17223/23088451/8/13}

Renat Z. Useev, Samara Law Institute of the Federal Penitentiary Service of the Russian Federation (Samara, Russian Federation). E-mail: crimjust@mail.ru

Keywords: multiple regime, hybridism, complexity, correctional facility, correctional system.

The detachment system in the organizational managerial aspect is expanding and enlarging, as an experiment is developing in a number of correctional facilities of the territorial bodies of the Federal Penitentiary Service of Russia to introduce a model of correctional centres for convicts. The centres are formed from two or three detachments of convicts that, as a rule, are accommodated in one residential building or in an isolated section. However, the Concept of the Development of the Penitentiary Service until 2020 has retained a point that placing convicts and their simultaneous presence in multi-lodging dormitories makes it impossible to prevent undesirable contacts between them. Thus, the current principles of separate detention of convicts do not allow to effectively solve this contradiction. In this regard, the author believes that the new correctional centres, though being experimental, should take into account the provisions of the abolished theoretical models of colonies-settlements with the usual and intensive supervision the RF Federal Penitentiary Service developed in 2011. According to these models, the main accommodation of convicts was a room for 6 people, not a dormitory. Thus, over the past 15 years, Russian correctional facilities have made a significant step towards multi-regime functioning. It seems that their multi-regime functioning should form the basis of a new hybrid type of a correctional institution. For this, the typology of prison should be decisive.

\section{REFERENCES}

1. Utkin, V.A. (2014) «Multiregime» correctional facilities: reality and prospects. Vestnik Kuzbasskogo instituta FSIN RossiiBulletin of the Kuzbass Institute. 4. pp. 9-17. (In Russian).

2. Utkin, V.A. (2014) Hybrid correctional facilities and international standards. Ugolovno-ispolnitel'noe pravo - Penal Law. 2 (18). pp. 7-11. (In Russian).

3. Gorban', D.V. (2015) «Kompleksnye» ispravitel'nye uchrezhdeniya v penitentsiarnoy sisteme Rossii na sovremennom etape ee reformirovaniya ["Complex" correctional institutions in the penitentiary system of Russia at the present stage of its reform]. Aktual'nye voprosy bor'by s prestupleniyami. 1. pp. 38-43.

4. Utkin, V.A. (2008) «Tyuremnyy» vektor v ugolovno-ispolnitel'noy sisteme [The "prison" vector in the penitentiary system]. Otechestvennye zapiski. 2 (41). pp. 149-156.

5. Averkina, K.V. (2015) Geografiya i ekonomika rossiyskoy penitentsiarnoy sistemy [Geography and economy of the Russian penitentiary system]. Demoskop Weekly. 651-652. pp. 7.

6. Reymer, A.A. (2011) Conception of Development of the Penal System of the Russian Federation till 2020 - Major Programme Document for Reforming Domestic Penitentiary System. Vestnik Vladimirskogo yuridicheskogo instituta Bulletin of Vladimir Law Institute. 2. pp. 4. (In Russian).

7. Seliverstov, V.I. (2015) Kuda sotsial'nyy lift teper' vyvezet eks-direktora FSIN [Where will the social elevator now take the ex-director of the FSIN]. Nezavisimaya gazeta. 07 April.

8. Petrov, I. (2015) FSIN likvidiruet i reorganizuet 100 koloniy [FSIN liquidates and reorganizes 100 colonies]. Rossiyskaya gazeta. 05 June.

9. Prestuplenie i nakazanie. (2016) Obespecheno stabil'noe funktsionirovanie UIS [The stable functioning of the penitentiary service is ensured]. Prestuplenie i nakazanie. 4. pp. 3-5.

10. Useev, R.Z. (2014) Concept, forms and boundaries of penal fortification. Ugolovno-ispolnitel'noe pravo - Penal Law. 1. pp. 38-41. (In Russian).

11. Nechaev, A.D. \& Usalev, V.V. (2015) [Problems of establishing institutions that execute sentences in the form of arrest]. Voprosy sovremennoy yurisprudentsii [Issues of modern jurisprudence]. Proc. of the XLVII international conference. 3 (45). Novosibirsk: SibAK. pp. 92-96. (In Russian).

12. Zubkov, A.I. (2006) Ugolovno-ispolnitel'noe pravo Rossii: teoriya, zakonodatel'stvo, mezhdunarodnye standarty, otechestvennaya praktika kontsa XIX - nachala XXI veka [Russia's penal law: theory, legislation, international standards, domestic practice of the end of the nineteenth and beginning of the 21st centuries]. Moscow: Norma.

13. Utkin, V.A. (2016) Penitentiary Standards of the Council of Europe and Vectors of Reforming the Penal System. Ugolovnoispolnitel'naya sistema: pravo, ekonomika, upravlenie - Criminal-Executory System: Law, Economy, Management. 1. pp. 14-18. (In Russian).

14. RF Federal Penitentiary Service. (2008) Otchet FSIN Rossii (forma 8-UIS) o kolichestve ispravitel'nykh koloniy, lechebnykh ispravitel'nykh $i$ lechebno-profilakticheskikh uchrezhdeniy, bol'nits, chislennosti, sostave $i$ dvizhenii osuzhdennykh, soderzhashchikhsya v nikh za 2007 [Report of the Federal Penitentiary Service of Russia (Form 8-UIS) on the number of correctional colonies, medical correctional and therapeutic institutions, hospitals, the number, composition and movement of convicts in them for 2007]. Moscow: FSIN Rossii.

15. Rospravosudie. (2011) Reshenie po delu Dudinskogo rayonnogo suda Krasnoyarskogo kraya № 2-601/2011 M-559/2011 [Decision of the Dudinsk District Court of Krasnoyarsk Krai on case 2-601/2011 M-559/2011]. [Online] Available from: https://rospravosudie.com/court-dudinskij-rajonnyj-sud-krasnoyarskij-kraj-s/act-407292311/ (data obrashcheniya: 17.05.2016).

16. Russian Federation. (2015) O vnesenii izmeneniy v Kontseptsiyu razvitiya ugolovno-ispolnitel'noy sistemy Rossiyskoy Federatsii do 2020 goda: Rasporyazhenie Pravitel'stva RF ot 23.09.2015 № 1877-r [On the introduction of changes to the Concept of the development of the penal system of the Russian Federation until 2020: Order 1877-p of the Government of the Russian Federation of September 23, 2015]. Sobranie zakonodatel'stva Rossiyskoy Federatsii - Legislation Bulletin of the Russian Federation. - 40. Art. 5581. 
17. RF Federal Penitentiary Service. (2015) O provedenii eksperimenta po aprobatsii modeli Tsentra ispravleniya osuzhdennykh ispravitel'nogo uchrezhdeniya: Rasporyazhenie FSIN Rossii ot 30.04.2015 goda № 63-r [On the experiment on approbation of the model of the Correction Centre for convicts of a correctional institution: Order 63-r of the Federal Penitentiary Service of Russia of April 30, 2015]. [Online] Available from: http://www.fsin.su/Original_doc/model_ispravitelnogo_centra.doc. (Accessed: 17th May 2016).

18. RF Federal Penitentiary Service. (2011) Model' koloniy-poseleniy s obychnym i usilennym nablyudeniem. Informatsionnoe pis'mo FSIN Rossii ot 26.05.2011 № 5-9796-05t [Model of colonies-settlements with ordinary and intensive control. Information letter 5-9796-05t of the Federal Penitentiary Service of Russia of May 26, 2011]. Moscow: FSIN Rossii. 